\title{
TV-Based Caring Videophone System for the Elderly in the Smart Home Environment
}

\author{
Jingshuang Shen, Chongyang Zhang, and Chuanwen Jiang \\ College of Electronics \& Electrical Engineering, Shanghai Jiaotong University, Shanghai 200240, China \\ Correspondence should be addressed to Chuanwen Jiang; jiangcw@sjtu.edu.cn
}

Received 5 March 2013; Revised 20 May 2013; Accepted 29 May 2013

Academic Editor: Yong Fu

Copyright (C) 2013 Jingshuang Shen et al. This is an open access article distributed under the Creative Commons Attribution License, which permits unrestricted use, distribution, and reproduction in any medium, provided the original work is properly cited.

\begin{abstract}
A novel videophone system for the elderly-care application is proposed. Based on the detailed analysis of the elderly's physical and psychological characteristics, a TV-based caring videophone system for the elderly is developed: an embedded multimedia device is designed to implement the interactive video and audio processing and IP-based communication, in which TV is adopted as the display terminal to achieve a low-cost but high-quality service. Considering the user's convenience, many personalized designs, such as photo-based address book, photo-click-dialing, and touch pad based remote controller, are developed to make the proposed videophone system more intuitive and easy to use for the elderly. Based on Support Vector Machine (SVM) algorithms, an evaluation model is also developed with the data collected from the embedded multimedia device. It is useful to evaluate the physical and psychological health of the elderly.
\end{abstract}

\section{Introduction}

As the age of the world general population increases, more and more elderly people are staying alone. Statics indicate that the population that is 65 years or older throughout the world is steadily on the raise [1, 2]. It is estimated that by 2030 this particular group will be over four hundred million in China. Thus, the number of the elderly living alone will keep increasing substantially. Therefore the importance of elderly care in their own home as long as possible is crucial $[3,4]$. And the smart home elderly care has the potential to be a costeffective alternative, capable of providing quality health care and monitoring households for the elderly [5-7].

Various elderly-care approaches have been proposed recently. In [8], the authors proposed a sensor/actuator networks in smart homes for supporting the elderly and handicapped people. In [9], the authors analyzed the data of the questionnaire study and found that the rest rooms/bathrooms and kitchens inconvenient and even dangerous places for the elderly. In [10], the authors introduced the sensor technologies integrated in the smart home system for the elderly and developed a framework for the processing and communication of the extracted information. In [11], the authors suggested a smart home monitoring system based on intelligent wireless sensors network to provide a safe, sound, and secured living environment to the elderly. However, most the above approaches require sensors to be attached on the subjects under surveillance. It is inconvenient for the elderly taking the clothes with these sensors. There are also some approaches without the sensors. In [12], the authors developed a low-cost television-operating-state telemonitoring system in caring for elderly people living alone. However the authors supposed that a television-operating-state expresses the consistency of the rhythms of the long-established everyday rituals of a dweller.

There are also many elderly-care systems developed for the elderly, and most of the elderly-care systems focus on health and safety surveillance [13-15]. However, spiritual needs of the elderly are of the most importance. In China, with the one-child-policy, many families have only one child. Since there are many younger peoples nowadays who select to work and live in big cities, which are usually far away from their hometown and then their parents, the elderly, often live lonely. Thus, the thing that communicating with children and friends frequently and easily becomes one of the urgent spiritual needs for the elderly. Meanwhile, the elderly not only want to hear their relatives' voices but also want to see their facial expression. 


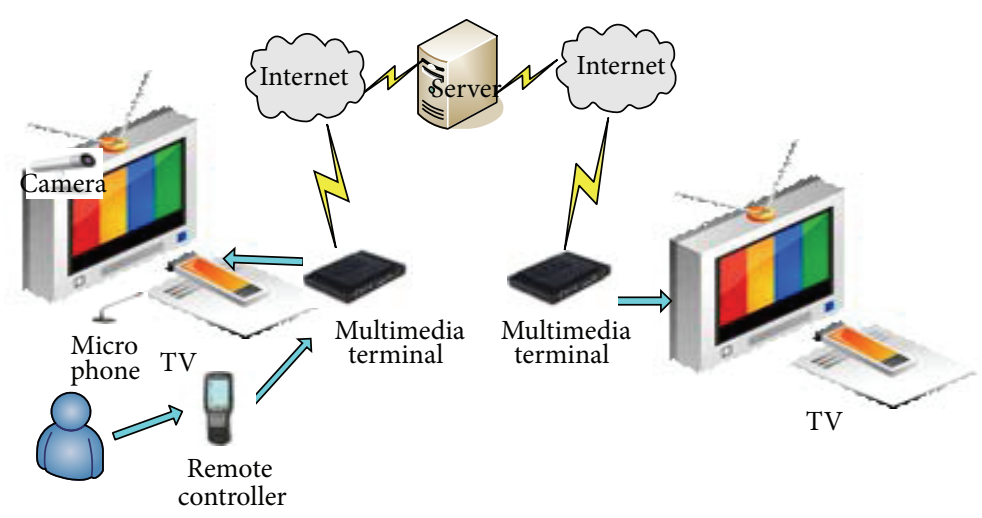

Figure 1: Overview of the whole videophone system.

Existing videophone systems can be classified into two types. The first type is the conventional videophone (also called video telephone), a telephone with a video screen, and is capable of full duplex (bidirectional) video and audio transmissions for communication between people in realtime. The early AT\&T Picturephones and the widest used mobile phones nowadays are belonging to this type. There are many advantages of the conventional video phone [16], however, the disadvantages such as expensiveness, complex operations of dial up, and small screen lead it difficult for the older age groups to use. The other type is PC-based video phone system, which consists of one computer with videophone software, and the necessary peripherals, such as microphones, and cameras, headsets. Compared with the conventional video phone, the PC-based videophone has advantages of having large screen and being inexpensive, but with the more complex software configuration and operation as the cost. Suffered with the "high-technology phobia," many elderly people are reluctant to use the cumbersome PC-based software, which makes the PC-based videophone difficult for the elderly to use.

In this work, a TV-based caring videophone system is developed for the elderly. Firstly, due to the fact that TV represents the main activity for the elderly people [17], it is adopted as the display terminal to achieve low-cost and highquality service in this work. Then, considering the using convenience for the elderly, personalized designs, including photo-based address book, photo-click dialing, and touch pad based remote controller, are provided to make it more intuitive and easy to use for the elderly. Due to the low-cost and caring design, the proposed videophone system is more suitable for the elderly than the existing videophone systems.

The rest of this paper is organized as follows. The system's hardware design and software design are given in Section 2. In Section 3, the design principles of caring videophone system based on detailed analysis of the elderly's physical and psychological characteristics are introduced firstly, and then the personalized design for the elderly is discussed. Evaluation model of the proposed system based on SVM algorithm is presented in Section 4. Section 5 gives the conclusion and future work.

\section{System Design}

2.1. Hardware Platform Design. To implement the caring videophone inexpensively, it is necessary to avoid any redesign and alteration on the current TV. One possible solution is to develop a low-cost embedded multimedia terminal, so as to implement the video-audio processing and communication, and provide the integrating connector for the necessary peripheral devices, such as TV, camera, microphone, communication server, and touch pad based remote controller. The architecture of the whole system is shown in Figure 1. Here the communication server acts as one communication agent for the IP-based video and audio interaction via internet. In this work, the software-based multiple point control unit (MCU) is also deployed on the server to provide the video conference function for the system. The wireless remote controller is used as the operation terminal for the elderly.

Figure 2 gives the block diagram of the multimedia terminal of the proposed videophone system. Video and Audio sampling module is used to collect the multimedia data and transmit them to Video and Audio codec. The multimedia processing (such as compress and decompress), IP communication (such as the protocol stacks of SIP, TCP/UDP, and IP), and peripheral management, are all implemented by one high-performance system on chip (SoC, Freescale i.MX27 is taken as the SoC in this work). The internet access units, including WiFi based wireless module, are integrated into the output module. User front-end module is used to collect the user's operation information. Figure 3 gives the circuit board of the embedded multimedia terminal. Table 1 reveals the specification requirements of the embedded system.

2.2. Software System Design. As TV-based caring videophone system is designed for the elderly, it only need to implement video communication and some basic functions such as address book and setting. The architecture of software is depicted in Figure 4. Initialization includes system initialization and registration. System initialization means processor initialization, SDRAM initialization, and I/O port initialization. Registration is responsible for registering with the server. Setting is responsible for configuring resolution, video format, IP of the server, and the terminal. Add new and edit 


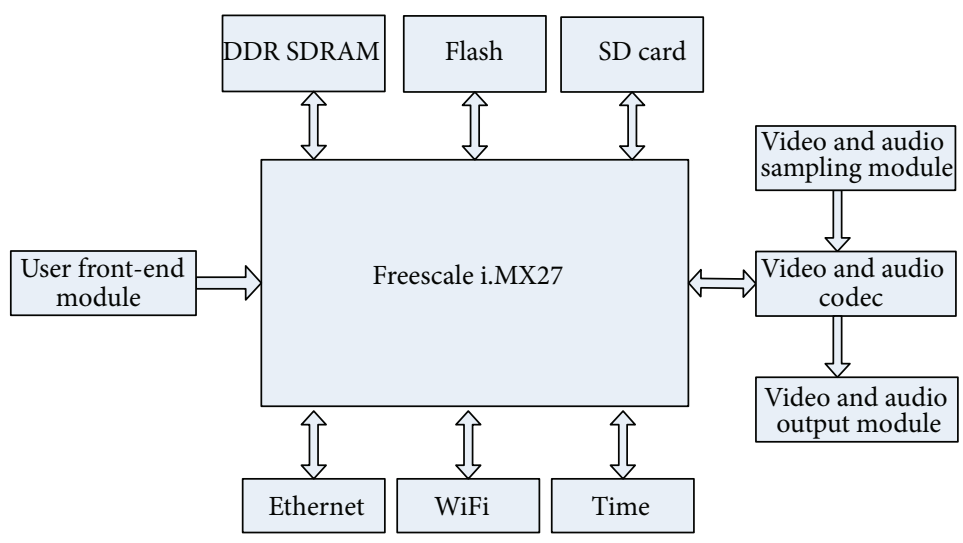

FIgURE 2: The block diagram of the multimedia terminal.

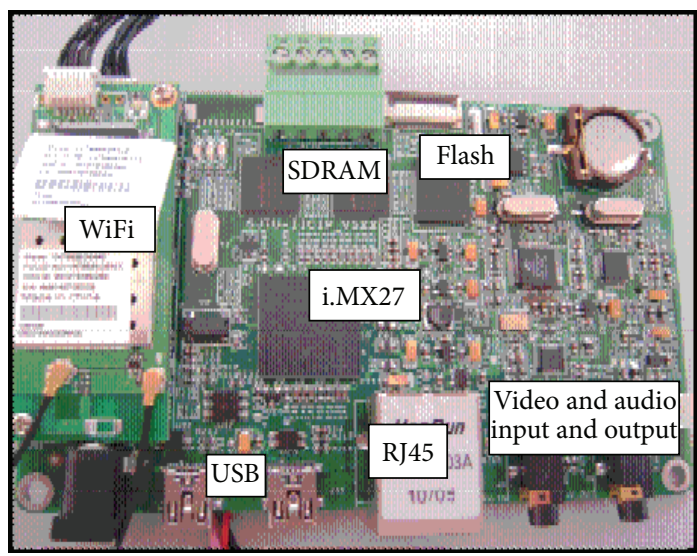

FIgURE 3: The circuit board of the embedded multimedia terminal.

TABLE 1: Embedded System Specification Requirements.

\begin{tabular}{lc}
\hline Characteristic & Specification \\
\hline Processor & i.MX27 \\
Processing performance & $400 \mathrm{MHZ}$ \\
Memory & $128 \mathrm{MB}, 32 \mathrm{bit}, 133 \mathrm{MHz}$ DDR \\
Flash & $128 \mathrm{MB}, 8 \mathrm{bit}$ \\
& Ethernet $>100 \mathrm{M}$ \\
Internet access & WiFi $>10 \mathrm{M}$ \\
& TVP5150AM1PBS (Ultralow-Power \\
Video and Audio codec & NTSC/PAL Video codec) \\
\hline
\end{tabular}

can help users add or edit content in the address book. Call is responsible for implementing video communication.

\section{Personalized Design for the Elderly}

3.1. The Elderly's Characteristics and Design Principles. The elderly have the unique characteristics different from the other people. For example, their eyesight and memory are poor and they need long time to accept new things. Therefore detailed analysis is necessary to design the suitable elderlycare products. Table 1 presents both the physical characteristics and psychological characteristics of the elderly (left side of the Table 2). Accordingly, the design principles of the elderly-oriented device or system can be concluded, as shown in the right side of Table 1 . Thus, to make the videophone system suitable for the elderly, the principles in Table 1 should be taken in the design processing.

According to the principles of design in Table 2, a few of personalized designs, such as user interface, photo-based address book, photo-click dialing, and touch-based remote controller, are developed in the caring videophone system.

3.2. Personalized Design of the User Interface. In order to give the elderly the comfortable visual feelings, many caring principles are considered in the design of the system software's user interface. Firstly, the icons number in each page is restricted to less than 10 [8], which can make the elderly feel it is simple, clear, and easy to use. Secondly, the light blue, which is neither fancy nor monotonous, is selected as the background color to calm the elderly's mentality. Finally, for different icons with text, different colors with appropriate contrast are adopted to make the elderly identify them easily 
TABLE 2: Design principles by analyzing the elderly's physical and psychological characteristics.

\begin{tabular}{|c|c|}
\hline The elderly's characteristics & Design principles \\
\hline $\begin{array}{l}\text { Vision: Hyperopia-serious decline in close vision, } \\
\text { astigmatism-focus difficulty, poor adjusting capacity to } \\
\text { adapt light—discomfort of glare. }\end{array}$ & $\begin{array}{l}\text { Interface: Appropriate color and bigger font sizes are needed } \\
\text { Illustration: (1) Graphic illustration which avoids fancy background } \\
\text { and unnecessary information is necessary. (2) It also should increase } \\
\text { the contrast between content and background. } \\
\text { Control: Surface of controller should not use highly reflective } \\
\text { material to avoid glare generation. }\end{array}$ \\
\hline $\begin{array}{l}\text { Thought: It is easy for the aged to form mindset resulting in } \\
\text { that they need to spend a long time to form a new concept. }\end{array}$ & $\begin{array}{l}\text { Interface: Concise text, graphic illustration, and enough time } \\
\text { information display make the aged fully comprehensive. }\end{array}$ \\
\hline Consumer attitude: economical, practical, and reliable. & Cost: Low. \\
\hline $\begin{array}{l}\text { Memory [18]: Sharp decline in short-term memory, poor } \\
\text { ability of converting short-term memory into long-term } \\
\text { memory and significant decrease in mechanical memorizing. }\end{array}$ & $\begin{array}{l}\text { Operation: The more meaningful memorizing, the better. It should } \\
\text { avoid using mechanical memorizing. }\end{array}$ \\
\hline $\begin{array}{l}\text { Habitus [19]: bone loss and being easy to fracture, poor } \\
\text { physical flexibility, clumsy action, and poor endurance. }\end{array}$ & $\begin{array}{l}\text { Controller: (1) It should operate in horizontal mode if the operator } \\
\text { needs strength for reducing the probability of falling. (2) Drop } \\
\text { resistance pads in the corners are necessary. }\end{array}$ \\
\hline $\begin{array}{l}\text { Touch: Thin skin and elasticity loss, weak ability of identify } \\
\text { texture and surface, and poor sensitivity of temperature }\end{array}$ & $\begin{array}{l}\text { Tip: The system should provide definite feedback to let the elderly } \\
\text { know what have been carried out when the buttons are pressed. } \\
\text { Controller: (1) It should be textured surface for easily grip. (2) It is } \\
\text { better to provide temperature adjustment. }\end{array}$ \\
\hline
\end{tabular}

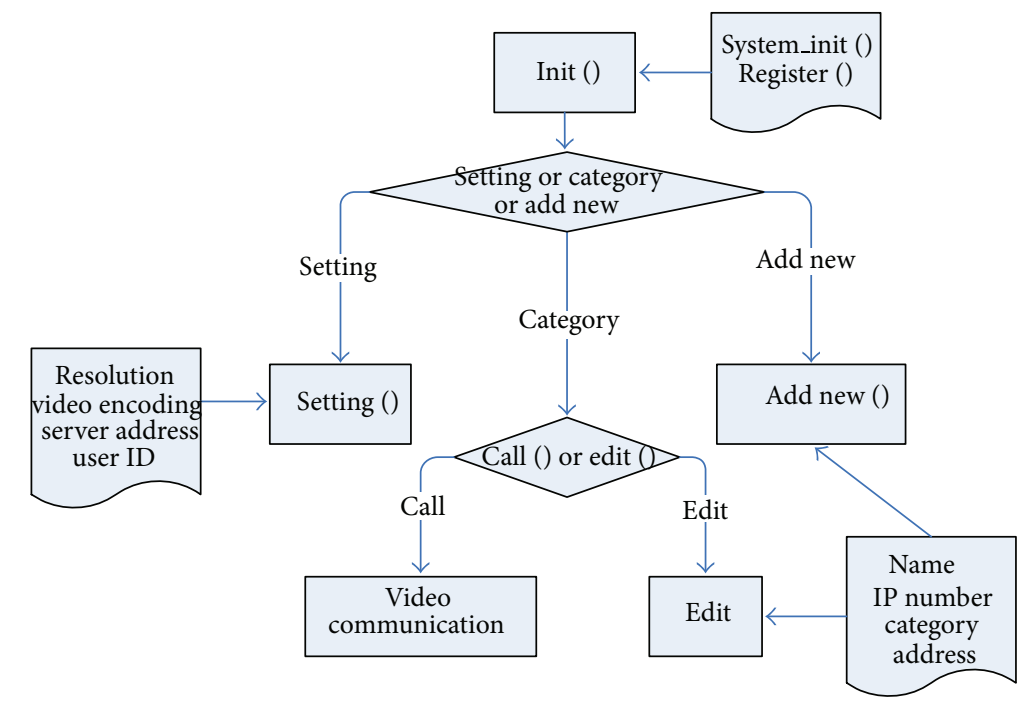

FIGURE 4: The architecture of software.

and clearly. One example of the user interface page is shown in Figure 5.

\subsection{Photo-Based Address Book and Photo-Click Dialing. Fig-} ure 6 shows photo-based Address book interface. It only lists photo, name, and IP number, which can make the elderly feel it is simple. Considering elderly people's poor vision, looking up conspicuous photos is proposed, instead of searching names in traditional way. It is also convenient for the elderly to find people whose names they do not remember or are identical in address book (e.g., sister in Figure 6). The design of photo-click-dial frees the elderly from remembering the long telephone numbers. They just need click photos to chat with the corresponding person. Thus, the operation becomes much easier for the elderly.
Since the connection of TV-based caring videophone systems via network, saving huge telephone fee is its significant advantage. IP-based communication and TV as the display terminal achieve low cost, which will make it popular among the elderly group.

3.4. Touch-Based Wireless Remote Controller. We select light blue as background color which can make the elderly pleasant. Meanwhile, strong contrast (between buttons and main color, between fonts and background) makes easy the elderly to distinguish the buttons. Function partition and key arrangement are reasonable. The upper part of panel is touch pad and the lower is button area. The upper part of button area is various function keys and the lower is number keys. A big "OK" button as the most frequently used key is designed 


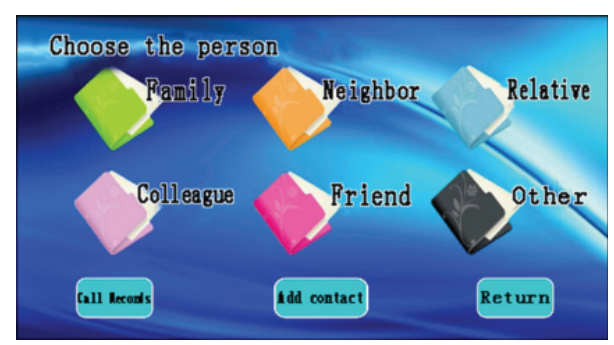

FIGURE 5: The initial interface page of the videophone.

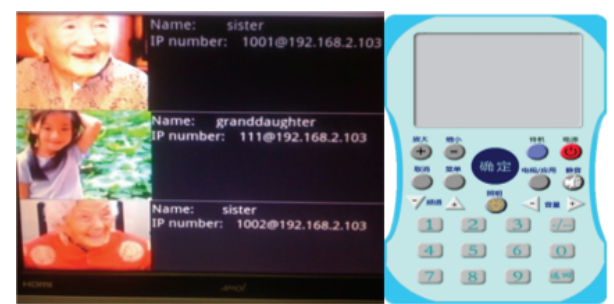

FIgure 6: Photo-based Address book (left) and the wireless remote controller (right).

at the center of function keys region. The size of every button and the font is appropriate.

Touch pad reduces the number of pressing keys and provides many fool operations such as menu tips and clickok, which can reduce probability of pressing wrong buttons. The controller has a built-small heater, which can adjust its temperature to make the elderly feel warm in winter. All of our design is based on the principles obtained by analyzing the elderly physical and psychological characteristics in detail. We make each operation as easy as possible and every interface much more comfortable.

In order to evaluate the total performance of the proposed videophone, comparison with the traditional videophone and PC-based videophone are taken in the following four aspects.

(a) Service quality: TV is taken as the display terminal, which can let the proposed videophone provide higher video quality than the others two systems.

(b) Operation Complexity: The caring designs, such as photo-based address book and photo-click dial, make the proposed system more intuitive and facilitative for the elderly. The touch-based remote controller can also make the operation more simple and intuitionistic.

(c) User Interface: The special elderly-oriented designs, such as the icon's number and size and background color, make the user interface of the proposed system more suitable for the elderly.

(d) Cost: Using the home-device TV and low-cost embedded multimedia terminal as the key components of the videophone, without the need of PC and the traditional but expensive videophone device, the proposed system is cheaper for the user.

Table 3 gives the conclusion results of the comparison. The following can be drawn from Table 3: comparing with the traditional videophone and PC-based videophone, the proposed system can provide higher display quality, more easily operation, more humanized user interface, and less cost, which make it more suitable for the elderly than the existing videophone system.

\section{Health Evaluating Model}

The other important function of the videophone system is to evaluate the physical and psychological health of the elderly. In this work, four physical and psychological characteristics are analyzed: normal, melancholy, irritability, and sick. These characteristics represent the state of the elderly's physical and psychological health. Different characteristic can be discriminated with the tiny habit change in the daily life. It is supposed that the elderly watch TV and call the family and other people with the videophone system. Since almost all the TV operations, such as the turning on/off TV channel changing, are implemented using the TV controller, these data can be collected, stored, and analyzed by the CPU (SoC on the multimedia terminal device) to get many useful TV-using information: the frequency of turning on/off TV, the time-length of each watch, the watching TV channel, the frequency of calling and the time-length of each call, and so forth. Considering the fact that TV represents the main activity for the elderly people, then the daily TV-usinginformation can be used to evaluate the psychological health, which can be shown in Figure 7.

The collected TV-using-information are then taken as the input data of one Support Vector Machine (SVM) based health evaluating model. This model can be developed and trained off-line, while used in this proposed videophone system to realize real-time health detection.

Among the data classification intelligent algorithms, SVM has recently achieved a great success in the forecasting and evaluating system [20]. The SVM was first introduced by Vapnik in the 1990s for classification and has been successfully applied to the problems of pattern classification [21], particularly the classification of two different categories of patterns. The fundamental principle of classification using the SVM is to separate the two categories of patterns as far as possible. It is based on the structural risk minimization principle incorporating capacity control to prevent overfitting and thus is a partial solution to the bias-variance trade-off dilemma. About the linear separable problem, the optimal classification function is as follows:

$$
\begin{aligned}
f(\omega) & =\operatorname{sgn}\{(\omega x+b)\} \\
& =\operatorname{sgn}\left\{\sum_{i=1}^{n} \alpha_{i}^{*} y_{i}\left(x_{i}, x\right)+b\right\},
\end{aligned}
$$

where $x_{i}$ is the sample vector, $y_{i}$ is the sample classification; $\alpha$ is the corresponding optimal solution for support vector, and $b$ is deviation. The value of $b$ can be solved from the constraint condition $\alpha_{i}\left[y_{i}\left(\omega x_{i}+b\right)-1\right]=0$. The basic idea of the SVM is to map data $x$ into a higher-dimensional feature space via a nonlinear mapping. Then the linear classification (regression) in the high-dimensional space is equivalent to the nonlinear 
TABLE 3: Comparison between the proposed videophone and the other two videophones.

\begin{tabular}{lccr}
\hline & Traditional videophone & PC-based videophone & Proposed videophone \\
\hline Service quality (display resolution) & Low & Moderate & High \\
Operation complexity & Complex & Complex & Easy \\
User interface & Young oriented & Young oriented & Elderly oriented \\
Cost & High & High & Low \\
\hline
\end{tabular}

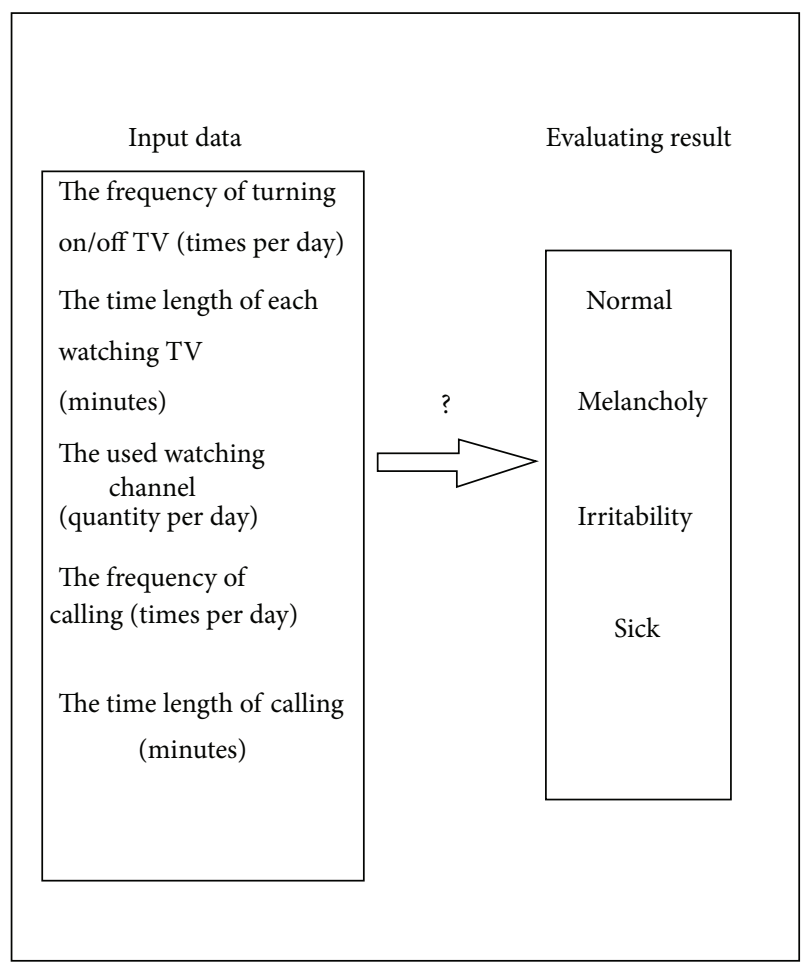

FIGURE 7: Evaluating the physical and psychological health using TV-using information.

classification (regression) in the low-dimensional space. The transform is simplified of SVM by using the kernel function. Then the classification function is as follows:

$$
f(\omega)=\operatorname{sgn}\left(\sum_{i=1}^{n} \alpha_{i}^{*} y_{i} K\left(x_{i}, x\right)+b\right)
$$

where the function $K$ is the kernel function. In this study, we choose the radial basis function (RBF) as the kernel function, which can be described as follows:

$$
k\left(x_{i}, x_{j}\right)=\exp \left(-\gamma\left\|x_{i}-x_{j}\right\|^{2}\right) .
$$

SVM is the two-class classifier. However, the multiclass classifier is required to solve the practical problem. Consider a set of $n$ samples is divided into $k$ categories. $x_{i}$ is the sample and $y_{i}$ is the sample type as $\left(x_{i}, y_{i}\right), i=1,2, \ldots, n, x_{i} \in R^{n}$, $y_{i} \in\{1,2, \ldots, k\}$.

In this paper, we select 50 set samples, including 40 set training samples and 10 testing samples, to test and verify the performance of the proposed health evaluating model.
TABLE 4: The average detection accuracy comparison between the SVM MODEL and the other two methods.

\begin{tabular}{lcccc}
\hline & Normal & Melancholy & Irritability & Sick \\
\hline SVM & $94.3 \%$ & $91.4 \%$ & $90.5 \%$ & $95.6 \%$ \\
ANN & $90.8 \%$ & $88.2 \%$ & $89.1 \%$ & $93.5 \%$ \\
GA & $92.1 \%$ & $90.7 \%$ & $88.6 \%$ & $93.9 \%$ \\
\hline
\end{tabular}

Besides SVM algorithm, Artificial Neural Network algorithm (ANN) and Genetic Algorithm (GA) also are also selected as the reference classifiers to compare their performance. The samples are the same for the three algorithms. In this paper, we select 10 set samples at random and calculate classified accuracy with SVM, ANN, and GA models. The result of the experiments shows that the SVM-based model is more accurate than other methods: the detection accuracy of SVM model is higher than that of other two methods in all the four kinds of psychological health. Table 4 gives the detailed result of SVM model compared with the other models.

\section{Conclusion}

A TV-based caring videophone system for the elderly is developed in this work. Many special and caring designs, such as photo-based address book, photo-click-dialing, and touch pad based remote controller, are developed in the proposed videophone system, which makes the proposed system more intuitive and easy to use for the elderly. Based on SVM algorithm, the model is also developed which can evaluate the physical and psychological health of the elderly. The result shows that this model can achieve the result more accurately than the other intelligent models. However, there is a lot of room to improve for the model. First, an online evaluating system would be developed. The result would be shown in the videophone system at real time. Second, more sensors data should be gathered including power consumption and door contacts in the smart homes environment.

\section{Acknowledgments}

This work was supported by the NSF of China under grant no. 61001147 and by the China National Key Technology R\&D Program under Grant no. 2012BAH07B01.

\section{References}

[1] A. Gaddam, S. C. Mukhopadhyay, and G. S. Gupta, "Trial \& experimentation of a smart home monitoring system for elderly," in Proceedings of the IEEE International Instrumentation and 
Measurement Technology Conference (I2MTC '11), pp. 849-854, May 2011.

[2] Z. A. Khan and W. Sohn, "Abnormal human activity recognition system based on R-transform and kernel discriminant technique for elderly home care," IEEE Transactions on Consumer Electronics, vol. 57, no. 4, pp. 1843-1850, 2011.

[3] X. Zhang, H. Wang, and Z. Yu, "Toward a smart home environment for elder people based on situation analysis," in Proceedings of the Symposia and Workshops on Ubiquitous, Autonomic and Trusted Computing, pp. 7-12, October 2010.

[4] A. Gaddam, S. C. Mukhopadhyay, and G. S. Gupta, "Smart home using optimized number of wireless sensors for elderly care," in Proceedings of the Applied Electromagnetics Conference (AEMC '09), December 2009.

[5] J.-Y. Son, J.-H. Park, K.-D. Moon, and Y.-H. Lee, "Resourceaware smart home management system by constructing resource relation graph," IEEE Transactions on Consumer Electronics, vol. 57, no. 3, pp. 1112-1119, 2011.

[6] C. Fabbricatore, M. Zucker, S. Ziganki, and A. P. Karduck, "Towards an unified architecture for smart home and ambient assisted living solutions: a focus on elderly people," in Proceedings of the 5th IEEE International Conference on Digital Ecosystems and Technologies (DEST '11), pp. 305-311, Daejeon, Republic of Korea, June 2011.

[7] D.-M. Han and J.-H. Lim, "Smart home energy management system using IEEE 802.15.4 and zigbee," IEEE Transactions on Consumer Electronics, vol. 56, no. 3, pp. 1403-1410, 2010.

[8] S. Dengler, A. Awad, and F. Dressler, "Sensor/actuator networks in Smart Homes for supporting elderly and handicapped people," in Proceedings of the 21st International Conference on Advanced Information Networking and Applications Workshops (AINAW'07), pp. 863-868, May 2007.

[9] M.-S. Kang, K. M. Kim, and H.-C. Kim, "A questionnaire study for the design of smart home for the elderly," in Proceedings of the Mobile E-Health for Developing Countries and 8th International Conference on E-Health Networking, Applications and Services (HEALTHCOM '06), pp. 265-268, August 2006.

[10] A. Arcelus, R. Goubran, M. H. Jones, and F. Knoefel, "Integration of smart home technologies in a health monitoring system for the elderly," in Proceedings of the 21st International Conference on Advanced Information Networking and ApplicationsWorkshops/Symposia (AINAW'07), pp. 820-825, May 2007.

[11] A. Gaddam, S. C. Mukhopadhyay, and G. S. Gupta, "Towards the development of a cognitive sensors network-based home for elder care," in Proceedings of the 6th International Conference on Wireless and Mobile Communications (ICWMC '10), pp. 484491, esp, September 2010.

[12] K. Nakajima, A. Kamiya, H. Matsui et al., "Telemonitoring system of television's operation state for elderly people living alone," in Proceedings of the Society of Instrument and Control Engineers Annual Conference (SICE '07), pp. 303-304, September 2007.

[13] K. Raij and P. Lehto, "Caring TV as a service design with and for elderly people," Studies in Computational Intelligence, vol. 142, pp. 481-488, 2008.

[14] F. Grossi, G. Matrella, I. De Munari, and P. Ciampolini, "A flexible home automation system applied to elderly care," in Proceedings of the Digest of Technical Papers International Conference on Consumer Electronics (ICCE '07), January 2007.

[15] S. Takahashi, S. Maeda, N. Tsurda, and T. Morimoto, "A home health care system for elderly people," Science and Technology, vol. 2, pp. 97-102, 2003.
[16] M. Pattison and A. Stedmon, "Inclusive design and human factors: designing mobile phones for older users," PsychNology Journal, vol. 4, no. 3, pp. 267-284, 2006.

[17] M. Ghorbel, F. Arab, and M. Mokhtari, "Assistive housing: case study in a residence for elderly people," in Proceedings of the 2nd International Conference on Pervasive Computing Technologies for Healthcare (PervasiveHealth '08), pp. 140-143, fin, February 2008.

[18] H. Jing-heng, Health Education, Fudan Uniberstiy Press, Shanghai, China, 4th edition, 2006.

[19] Y. Hioka, M. Okamoto, K. Kobayashi, Y. Haneda, and A. Kataoka, "A display-mounted high-quality stereo microphone array for high-definition videophone system," IEEE Transactions on Consumer Electronics, vol. 54, no. 2, pp. 778-786, 2008.

[20] C.-W. Hsu and C.-J. Lin, "A comparison of methods for multiclass support vector machines," IEEE Transactions on Neural Networks, vol. 13, no. 2, pp. 415-425, 2002.

[21] V. Vapnik, The Nature of Statistical Learning Theory, Springer, New York, NY, USA, 1995. 

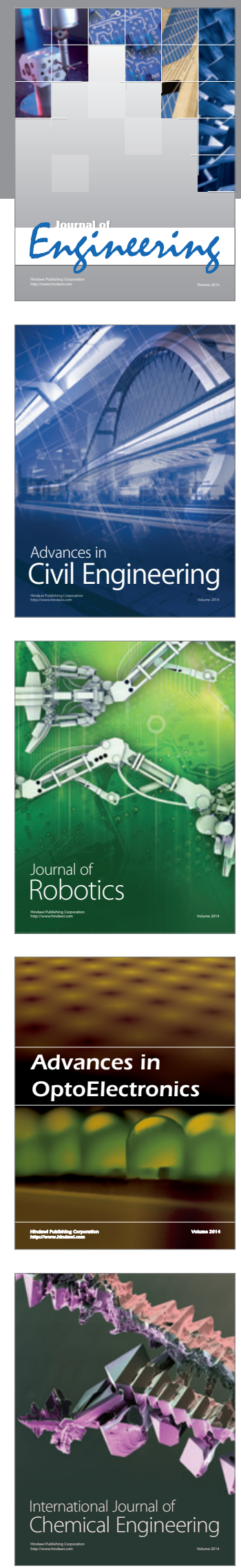

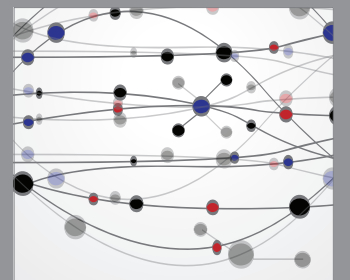

The Scientific World Journal
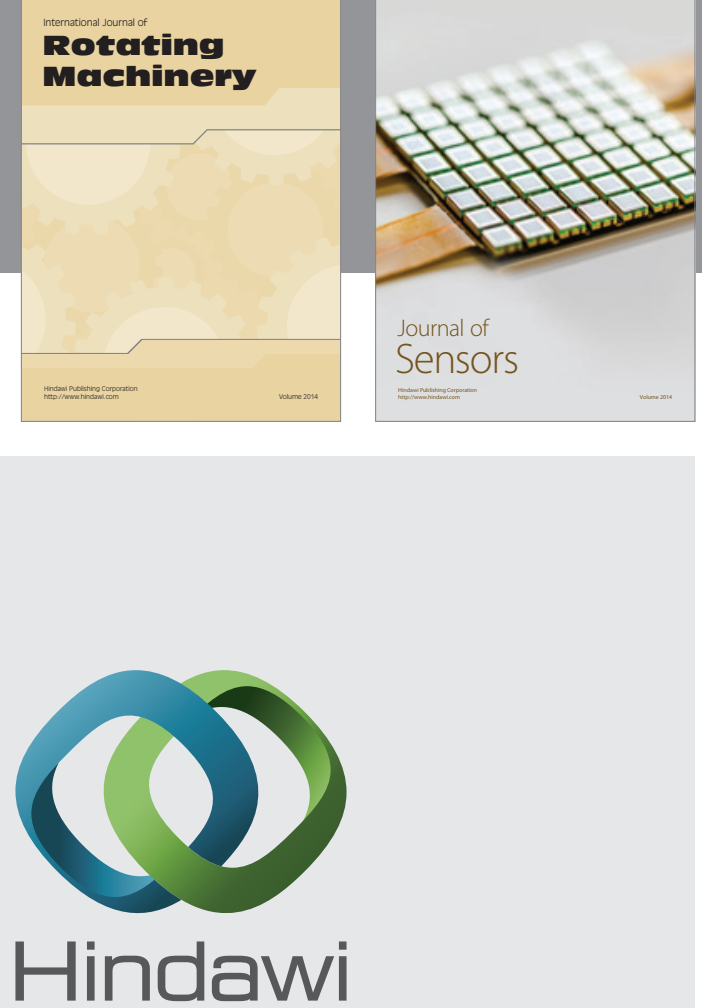

Submit your manuscripts at http://www.hindawi.com
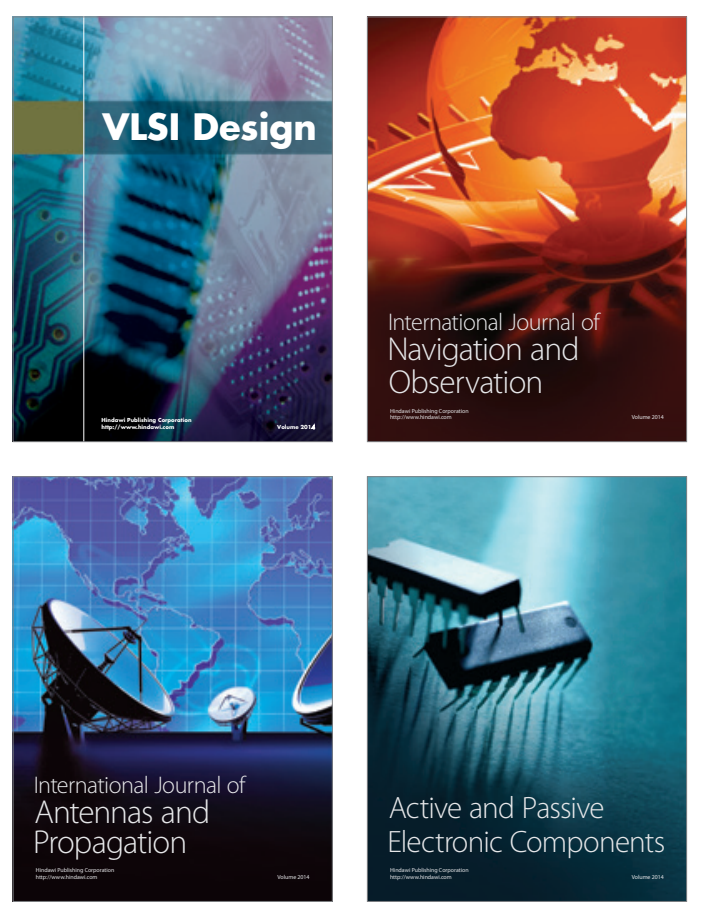
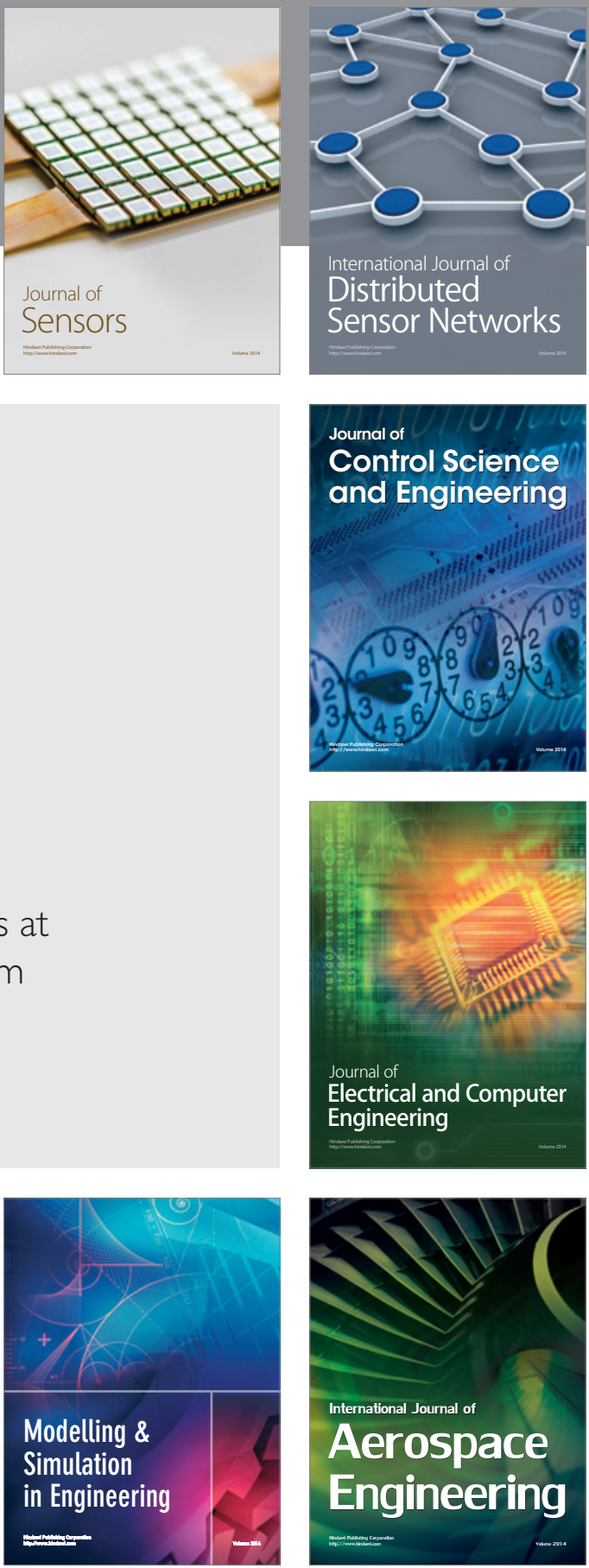

Journal of

Control Science

and Engineering
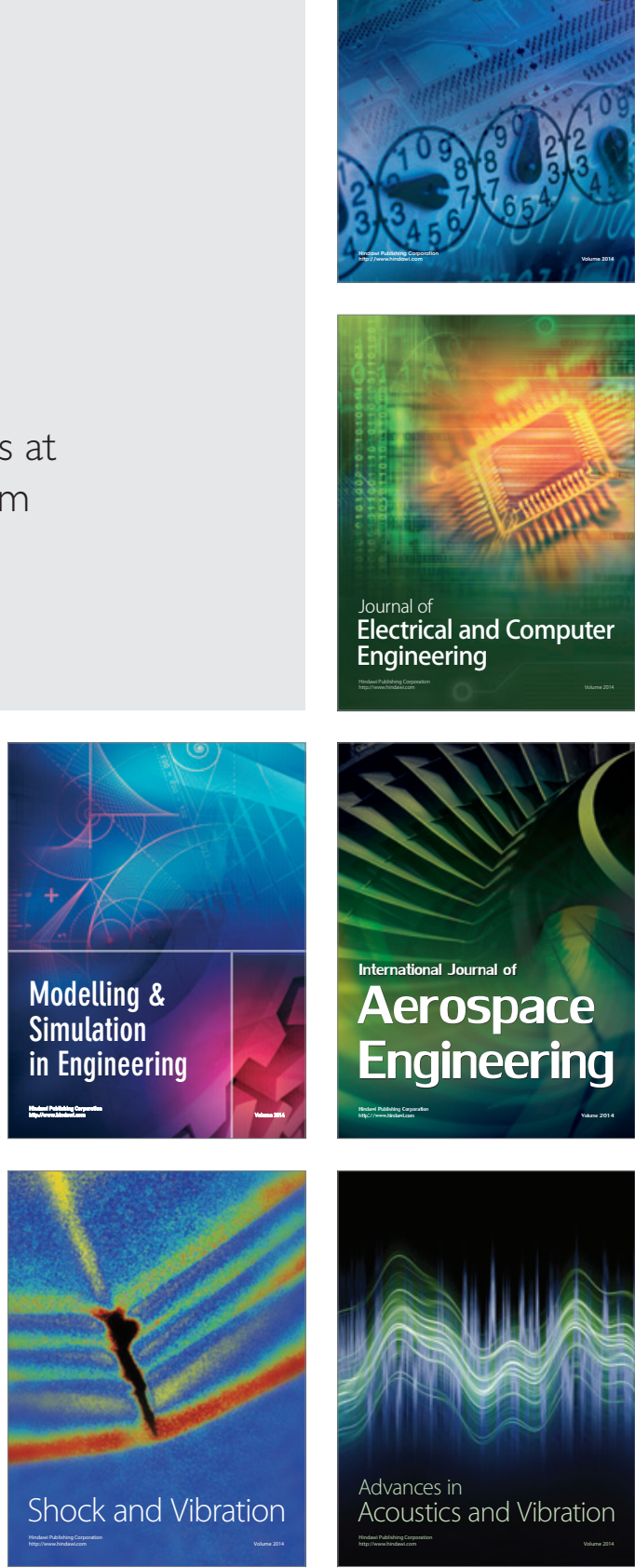